Aline ZYMAn De ANDRADE ${ }^{1}$

JHENIFER KLIEMCHEN RODRIGUES ${ }^{2}$

LUCIANA AZÔR DiB ${ }^{3}$

Gustavo Salata Romão ${ }^{4}$

RUI Alberto Ferrian ${ }^{5}$

AlCEU Afonso JoRdÃo JunIOR ${ }^{6}$

Paula Andrea de Albuquerque Salles

NAVARRO
Artigo original

Palavras-chave

Endometriose

Estresse oxidativo

Peroxidação de lipídeos

Glutationa

Vitamina E

Infertilidade feminina

Keywords

Endometriosis

Oxidative stress

Lipid peroxidation

Glutathione

Vitamin E

Infertility, female

Correspondência:

Paula Andrea de Albuquerque Salles Navarro Av. Bandeirantes, 3900 - Monte Alegre (EPP 14049-900 - Ribeirão Preto (SP), Brasil

Fone: (16) 3602-2821

Fax: (16) 3602-2810

E-mail: pnavarro@fmrp.usp.br

Recebido

$6 / 5 / 2010$

Aceito com modificacōoes $31 / 5 / 2010$

\section{Marcadores séricos de estresse oxidativo em mulheres inférteis com endometriose}

\author{
Serum markers of oxidative stress in infertile women with endometriosis
}

\section{Resumo}

OBJETIVO: comparar marcadores séricos de estresse oxidativo entre pacientes inférteis com e sem endometriose e avaliar a associação destes marcadores com o estadiamento da doença. MÉTODOS: estudo prospectivo envolvendo a inclusão consecutiva de 112 pacientes inférteis, não-obesas, com idade inferior a 39 anos, divididas em dois grupos: Endometriose (n=48, sendo 26 com endometriose mínima e leve - Estádio I/II e 22 com endometriose moderada e grave - Estádio III/IV) e Controle (n=64, com fator tubário e/ou masculino de infertilidade). Durante a fase folicular precoce do ciclo menstrual, foram coletadas amostras sanguíneas para análise dos níveis séricos de malondialdeído, glutationa e níveis totais de hidroperóxidos, por espectrofotometria e vitamina E, por cromatografia líquida de alto desempenho. Os resultados obtidos foram comparados da seguinte forma: os grupos endometriose versus controle; endometriose estádio I/II e controle, endometriose estádio III/IV e controle e entre os dois subgrupos de endometriose. Em todas as análises, foi considerado o nível de significância de $5 \%(p<0,05)$. RESULTADOS: os níveis de vitamina E e glutationa foram mais baixos no soro de mulheres inférteis com endometriose moderada/grave $(21,7 \pm 6,0 \mu \mathrm{Mol} / \mathrm{L}$ e 159,6 $6 \pm 77,2 \mathrm{nMol} / \mathrm{g}$ proteína, respectivamente) quando comparadas a mulheres com endometriose mínima e leve $(28,3 \pm 14,4 \mu \mathrm{Mol} / \mathrm{L}$ e $199,6 \pm 56,1 \mathrm{nMol} / \mathrm{g}$ proteína, respectivamente). Os níveis totais de hidroperóxidos foram significativamente mais elevados no grupo endometriose $(8,9 \pm 1,8 \mu \mathrm{Mol} / \mathrm{g}$ proteína) em relação ao Grupo Controle $(8,0 \pm 2 \mu \mathrm{Mol} / \mathrm{g}$ proteína)

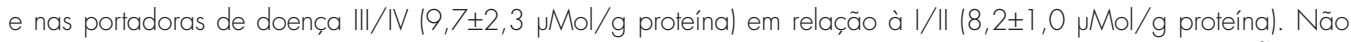
se observou diferença significativa nos níveis séricos de malondialdeído entre os diversos grupos. CONCLUSÕES: foi evidenciada uma associação positiva entre infertilidade relacionada à endometriose, avanço do estadiamento da doença e aumento dos níveis séricos de hidroperóxidos, sugerindo aumento da produção de espécies reativas em portadoras de endometriose. Esses dados, associados à redução dos níveis séricos de vitamina E e glutationa, sugerem a ocorrência de estresse oxidativo sistêmico em portadoras de infertilidade associada à endometriose.

\section{Abstract}

PURPOSE: to compare serum markers of oxidative stress between infertile patients with and without endometriosis and to assess the association of these markers with disease staging. METHODS: this was a prospective study conducted on 112 consecutive infertile, non-obese patients younger than 39 years, divided into two groups: Endometriosis $(n=48$, 26 with minimal and mild endometriosis - Stage I/II, and 22 with moderate and severe endometriosis - Stage III/IV) and Control ( $n=64$, with tubal and/or male factor infertility). Blood samples were collected during the early follicular phase of the menstrual cycle for the analysis of serum malondialdehyde, glutathione and total hydroxyperoxide levels by spectrophotometry and of vitamin E by high performance liquid chromatography. The results were compared between the endometriosis and control groups, stage I/II endometriosis and control, stage III/IV endometriosis and control, and between the two endometriosis subgroups. The level of significance was set at $5 \%(p<0.05)$ in all analyses. RESULTS: vitamin $\mathrm{E}$ and glutathione levels were lower in the serum of infertile women with moderate/severe endometriosis

Laboratório de Ginecologia do Hospital das Clínicas da Faculdade de Medicina de Ribeirão Preto, Setor de Reprodução Humana, Departamento de Ginecologia e Obstetrícia, Faculdade de Medicina de Ribeirão Preto, Universidade de São Paulo - FMRP-USP Ribeirão Preto (SP), Brasil; Laboratório de Nutrição e Metabolismo, Departamento de Clínica Médica, Faculdade de Medicina de Ribeirão Preto, Universidade de São Paulo - FMRP-USP - Ribeirão Preto (SP), Brasil.

' Pós-graduanda (Mestrado) do Departamento de Ginecologia e Obstetrícia da Faculdade de Medicina de Ribeirão Preto - USP Ribeirão Preto (SP), Brasil.

2 Pós-graduanda (Mestrado) do Departamento de Ginecologia e Obstetrícia da Faculdade de Medicina de Ribeirão Preto - USP Ribeirão Preto (SP), Brasil.

${ }_{3}^{3}$ Pós-graduanda (Mestrado) do Departamento de Ginecologia e Obstetrícia da Faculdade de Medicina de Ribeirão Preto - USP Ribeirão Preto (SP), Brasil.

${ }_{4}^{4}$ Professor Adjunto do Departamento de Medicina da Universidade Federal de São Carlos - UFSCar - São Carlos (SP), Brasil.

5 Professor Titular do Departamento de Ginecologia e Obstetrícia da Faculdade de Medicina de Ribeirão Preto - USP - Ribeirão Preto (SP), Brasil.

- Professor Doutor do Departamento de Clínica Médica da Faculdade de Medicina de Ribeirão Preto - USP - Ribeirão Preto (SP), Brasil.

7 Professora Doutora do Departamento de Ginecologia e Obstetrícia, Setor de Reprodução Humana, da Faculdade de Medicina de Ribeirão Preto - USP - Ribeirão Preto (SP), Brasil. 
$121.7 \pm 6.0 \mathrm{mMol} / \mathrm{L}$ and $159.6 \pm 77.2 \mathrm{nMol} / \mathrm{g}$ protein, respectively) compared to women with minimal and mild endometriosis $(28.3 \pm 14.4 \mathrm{mMol} / \mathrm{L}$ and $199.6 \pm 56.1 \mathrm{nMol} / \mathrm{g}$ protein, respectively). Total hydroxyperoxide levels were significantly higher in the endometriosis group (8.9 $1.8 \mathrm{\mu Mol} / \mathrm{g}$ protein) than in the Control Group $(8.0 \pm 2 \mu \mathrm{Mol} / \mathrm{g}$ protein) and among patients with stage III/IV disease $(9.7 \pm 2.3 \mu \mathrm{Mol} / \mathrm{g}$ protein) compared to patients with stage I/II disease (8.2 $1.0 \mathrm{\mu Mol} / \mathrm{g}$ protein). No significant differences in serum malondialdehyde levels were observed between groups. CONCLUSIONS: we demonstrated a positive association between infertility related to endometriosis, advanced disease stage and increased serum hydroxyperoxide levels, suggesting an increased production of reactive species in women with endometriosis. These data, taken together with the reduction of serum vitamin $E$ and glutathione levels, suggest the occurrence of systemic oxidative stress in women with infertility associated with endometriosis. The reproductive and metabolic implications of oxidative stress should be assessed in future studies.

\section{Introdução}

A endometriose é caracterizada pela presença de glândulas e/ou estroma endometrial fora da cavidade uterina e afeta entre 5 e $15 \%$ das mulheres em idade reprodutiva e entre 25 e $40 \%$ das mulheres inférteis ${ }^{1-3}$. Alguns autores sugeriram a possibilidade de a endometriose ser uma doença originada ou associada ao estresse oxidativo ${ }^{2,4-6} . \mathrm{Na}$ vigência de endometriose pélvica, haveria a ativação dos macrófagos na cavidade peritoneal, o que poderia promover aumento da produção de espécies reativas do oxigênio e nitrogênio e, consequentemente, estresse oxidativo, gerando peroxidação dos lipídios, de seus produtos de degradação e dos produtos formados pela sua interação com as lipoproteínas de baixa densidade e outras proteínas ${ }^{7}$. Os lipídios oxidados, ao se decomporem, gerariam produtos como o malondialdeído (MDA) e poderiam ser reconhecidos como corpos estranhos, desencadeando resposta antigênica com consequente produção de anticorpos ${ }^{8,9}$. Esse processo cursaria com danos oxidativos às hemáceas, às células endometriais e peritoneais, o que, por sua vez, estimularia o recrutamento e ativação de mais fagócitos mononucleares, perpetuando os danos oxidativos na cavidade pélvica ${ }^{10}$. O estresse oxidativo também danifica células mesoteliais e pode induzir o aparecimento de sítios de adesão para células endometriais, favorecendo o desenvolvimento e a progressão dos focos de endometriose ${ }^{11}$.

No sistema reprodutor feminino, diversos mecanismos biológicos conduzem ao desempenho harmônico das suas funções. Dentro desse contexto, encontramos entre os agentes moduladores dos processos fisiológicos do trato reprodutor feminino os radicais livres, que são substâncias com elétrons desemparelhados caracterizados pela alta capacidade de reagir com outros substratos, especialmente as proteínas, o DNA e os lipídios. Baixas concentrações de espécies reativas têm importância na modulação de inúmeros processos fisiológicos do trato reprodutivo feminino, como a maturação oocitária, a atresia folicular, a função do corpo lúteo, a interação gamética, a fertilização, o desenvolvimento e a implantação embrionária ${ }^{12,13}$. Porém, quando há um desequilíbrio entre os agentes pró-oxidantes (radicais livres) e os mecanismos antioxidantes de defesa do organismo, pode ocorrer o estresse oxidativo, que tem sido envolvido na etiopatogênese de diversas doenças reprodutivas e da infertilidade ${ }^{14}$.
A produção de radicais livres pode promover a peroxidação lipídica dos ácidos graxos poli-insaturados presentes nas membranas celulares, com produção de hidroxiperóxidos lipídicos, aldeídos e isoprostanos. O malondialdeído (MDA) é um desses produtos secundários da peroxidação lipídica que, por ser um produto estável, pode ser utilizado como medida cumulativa desse processo ${ }^{15,16}$. Apesar de os dados serem controversos, alguns autores evidenciaram aumento significativo das concentrações de peróxidos lipídicos no fluido peritoneal de portadoras de endometriose pélvica ${ }^{17}$. Todavia, não dispomos de dados referentes à análise deste marcador de estresse oxidativo no soro de mulheres com infertilidade relacionada à endometriose.

A vitamina E é um dos principais antioxidantes nãoenzimáticos, podendo tanto bloquear o início da peroxidação lipídica como inibir a sua propagação ${ }^{18}$. Em estudo recentemente publicado em nosso serviço, evidenciaram-se menores níveis séricos de vitamina $\mathrm{E}$ em portadoras de infertilidade relacionada à endometriose, após bloqueio hipofisário com agonista do hormônio liberador de gonadotrofinas $(\mathrm{GnRH})^{16}$. Todavia, não dispomos de dados de análise dos níveis sistêmicos deste antioxidante em ciclos naturais de mulheres inférteis com endometriose.

A glutationa, principal componente sulfidril nãoproteico em células de mamíferos, desempenha um papel fundamental na neutralização de peróxidos e na proteção celular contra o estresse oxidativo ${ }^{19}$. A glutationa é um tripeptídio presente tanto no estágio reduzido quanto no oxidado, cujos níveis são mantidos por síntese de novo catalisada por duas enzimas, uma das quais é inibida por compostos produzidos em resposta ao estresse oxidativo. Esse antioxidante está presente no oócito e no fluido tubário, e participa dos processos de maturação oocitária, descondensação espermática, ativação oocitária, além de desempenhar importante função permissiva para o desenvolvimento embrionário pré-implantação ${ }^{12,19}$. Uma das atividades antioxidantes da glutationa consiste em eliminar, indiretamente, o tocoferol oxidado ${ }^{18}$, importante para a reciclagem e manutenção de níveis fisiológicos de vitamina $\mathrm{E}$, essenciais para o combate ao estresse oxidativo ${ }^{18}$.

A avaliação do total de hidroperóxidos em uma dada amostra permite uma análise indireta da produção de espécies reativas ${ }^{20}$ que antecede tanto o maior consumo de antioxidantes não-enzimáticos como a vitamina $\mathrm{E}$ e a 
glutationa, por exemplo, a detecção de produtos do dano oxidativo, como a peroxidação lipídica.

Apesar de existirem evidências sugerindo presença de estresse oxidativo nos sítios dos implantes pélvicos endometriais, pouco se sabe sobre o status oxidativo sistêmico em portadoras de infertilidade relacionada à endometriose. Da mesma maneira, muito pouco é conhecido sobre a associação entre estadiamento da doença e os marcadores sistêmicos de estresse oxidativo. Neste sentido, objetivamos comparar quatro marcadores séricos de estresse oxidativo entre pacientes inférteis com endometriose e controles (infertilidade de causa tubária e/ ou masculina), aferidos na fase folicular precoce do ciclo menstrual, e avaliar a associação destes marcadores com o estadiamento da doença.

\section{Métodos}

Foi realizado um estudo prospectivo de Fevereiro de 2008 a Julho de 2009 junto ao Setor de Reprodução Humana do Departamento de Ginecologia e Obstetrícia da FMRP-USP. Este estudo foi submetido e aprovado pelo Comitê de Ética em Pesquisa e todas as pacientes que preencheram os critérios de inclusão e manifestaram o desejo de participar do projeto assinaram o termo de consentimento pós-informado previamente à inclusão no estudo.

Foram selecionadas consecutivamente todas as pacientes elegíveis que concordaram em participar do estudo, divididas em dois grupos: com endometriose ( $n=48$, sendo 13 com endometriose mínima - I, $13 \mathrm{com}$ endometriose leve - II, 11 com moderada - III e $11 \mathrm{com}$ endometriose grave - IV) e 64 pacientes controles. O grupo de estudo consistiu em pacientes com infertilidade secundária a endometriose diagnosticada por videolaparoscopia (segundo os critérios da American Society for Reproductive Medicine), subdivididas em portadoras de doença mínima/leve $(n=26)$ e moderada/grave $(n=22)$. O Grupo Controle foi representado por pacientes inférteis devido a fator masculino e/ou tubário. Todas as pacientes do Grupo Controle foram submetidas à videolaparoscopia diagnóstica como procedimento de rotina para investigação da infertilidade conjugal, sendo excluída a presença de endometriose e hidrossalpinge. Foram incluídas apenas pacientes com idade máxima de 38 anos, índice de massa corporal (IMC) menor que $30 \mathrm{~kg} / \mathrm{m}^{2}$ e nível sérico de hormônio folículo-estimulante (FSH) menor ou igual a $10 \mathrm{mUI} / \mathrm{mL}$. Foram critérios de exclusão: doenças crônicas como diabetes mellitus ou quaisquer outras endocrinopatias, doença cardiovascular, dislipidemia, lupus eritematoso sistêmico e outras doenças reumatológicas, infecção pelo vírus HIV, qualquer infecção ativa, tabagismo, uso de medicações hormonais e de anti-inflamatórios hormonais e não-hormonais nos últimos seis meses, previamente à inclusão no presente estudo.

Não foi observada diferença significativa entre os grupos avaliados (controle, endometriose, endometriose I/II e endometriose III/IV) com relação à média de idade $(33,3 \pm 3,9 ; 32,9 \pm 3,7 ; 32,6 \pm 3,8 ; 33,4 \pm 3,6$, respectiva-

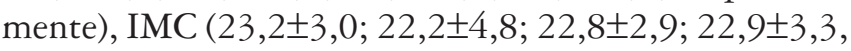
respectivamente) e FSH basal $(5,7 \pm 2,7 ; 6,0 \pm 3,1 ; 5,8 \pm 3,6$; $6,3 \pm 2,7$, respectivamente).

Foram coletadas amostras de sangue periférico das pacientes na fase folicular precoce do ciclo menstrual (terceiro ao quinto dias do ciclo), centrifugadas a $2600 \mathrm{x}$ g por 10 minutos e o soro armazenado a $-80^{\circ} \mathrm{C}$, para posterior determinação dos níveis séricos de malondialdeído (MDA), total de hidroperóxidos (FOX), vitamina E e glutationa, conforme descrito a seguir.

\section{Avaliação da peroxidação lipídica (MDA)}

O soro, previamente estocado, foi descongelado até atingir $37^{\circ} \mathrm{C}$. Cerca de $250 \mu \mathrm{L}$ de cada amostra foi misturado a $500 \mu \mathrm{L}$ de TCA-TBA-HCL (15\% de ácido tricloracético, $0,375 \%$ de ácido tiobarbitúrico e $0,25 \mathrm{~N}$ de ácido clorídrico) e aquecido em banho-maria por 15 minutos. Após resfriamento, o precipitado foi centrifugado a $3000 \mathrm{rpm}$ por 10 minutos. A absorbância do produto foi medida em espectofotômetro (Spectronic 601-Milto Roy) com comprimento de onda de $535 \mathrm{~nm}$. O cálculo da concentração das TBARS foi realizado considerando-se o coeficiente de absortividade molar do produto (E535=1,56 x $10^{-5} \mathrm{M}^{-1} \mathrm{~cm}^{1}$ ), sendo os resultados expressos em nmol/g proteína.

\section{Quantidade total de hidroperóxidos ( $\mathrm{FOX}_{1}$ )}

$\mathrm{O}$ sistema de teste $\mathrm{FOX}_{1}$ é baseado na oxidação do $\mathrm{Fe}^{+2}$ (íon ferroso) a $\mathrm{Fe}^{+3}$ (íon férrico) por vários tipos de peróxidos contidos nas amostras a serem analisadas. $\mathrm{Na}$ presença de xylenol orange forma-se um complexo colorido (xylenol orange-férrico) de cor azul púrpura, cuja absorbância pode ser medida. A determinação do total de hidroperóxidos foi realizada segundo metodologia descrita porGalli et al. ${ }^{20}$. A absorbância foi medida em $560 \mathrm{~nm}$ e o resultado foi expresso em $\mu \mathrm{mol} / \mathrm{g}$ proteína.

O malondialdeído e o FOX foram expressos por $\mathrm{g}$ de proteína, que foi determinada utilizando-se o kit Proteínas Totais Labtest ${ }^{\circledR}$. O princípio dessa metodologia está na reação entre o íon cobre do reagente biureto, que reage em contato com as ligações peptídicas da proteína, produzindo uma cor púrpura, que deve ser lida a $540 \mathrm{~nm}$ no espectrofotômetro.

\section{Vitamina E}

A determinação da concentração de vitamina $\mathrm{E}$ ( $\alpha$-tocoferol) no soro foi realizada segundo o método descrito 
por Arnaud et al. ${ }^{21}$. Uma amostra de $200 \mu \mathrm{L}$ de soro foi homogeneizada em $200 \mu \mathrm{L}$ de etanol e homogeneizada por 5 segundos em vórtex. Em seguida, foi colocada em $400 \mu \mathrm{L}$ de n-hexano, agitada por 1 minuto e 10 segundos e centrifugada a $3500 \mathrm{rpm}$ por 5 minutos. Uma alíquota de $200 \mu \mathrm{L}$ do sobrenadante (n-hexano) foi pipetada em tubo de ensaio, que posteriormente foi seco em nitrogênio, e ressuspensa em $200 \mu \mathrm{L}$ de fase móvel, composta por acetonitrila/diclorometanol/metanol (70:10:20, v/v/v) e filtrada. Para a determinação das concentrações da vitamina E, foi utilizado um HPLC modelo Shimadzu LC-9 ${ }^{A}$, sendo a leitura realizada por espectofotometria a $292 \mathrm{~nm}$. Os resultados foram expressos em $\mu \mathrm{mol} / \mathrm{L}$.

\section{Glutationa (GSH)}

A GSH do soro foi medida por um método descrito originalmente por Ellman ${ }^{22}$ e modificado por $\mathrm{Hu}^{23}$, no qual os grupos tióis interagem com o ácido ditionitrobenzoico (DTNB) formando um ânion altamente colorido com um pico máximo a $412 \rho \mathrm{M}\left(\mathrm{e} 412=13,600 \mathrm{M}^{-1} \mathrm{~cm}^{-1}\right)$. Nesse ensaio, uma alíquota de $25 \mu \mathrm{L}$ de soro foi misturada a 1 $\mathrm{mL}$ de tris-EDTA buffer $(25 \mathrm{nmol} / \mathrm{L}$ Tris-base, $20 \mathrm{mmol} / \mathrm{L}$ EDTA, pH 8,2) e a leitura da absorbância foi realizada em um comprimento de onda de $412 \rho \mathrm{M}$. Após essa leitura, uma alíquota de $25 \mu \mathrm{L}$ de solução estoque de DTNB (10 nmol/L em etanol absoluto) foi adicionada à solução, mantendo-se a temperatura ambiente durante 15 minutos. Após esse período, nova leitura foi realizada utilizando como branco o DTNB. A curva para esta leitura foi realizada em duplicata com DTNB, EDTA e três diferentes concentrações de GSH. O resultado foi expresso em $\mathrm{nmol} / \mathrm{L}$.

Inicialmente, os grupos endometriose e controle foram analisados comparativamente quanto aos níveis séricos de malondialdeído (MDA) e glutationa, por meio do teste $t$ não-pareado, e vitamina $\mathrm{E}$ e total de hidroperóxidos $\left(\mathrm{FOX}_{1}\right)$, por meio do teste de Mann-Whitney. Posteriormente, os subgrupos da endometriose (estádios I/II e III/IV) foram comparados para MDA, FOX e glutationa pelo teste $t$ não-pareado e para vitamina $\mathrm{E}$ pelo teste de MannWhitney. Os grupos endometriose I/II, endometriose III/ IV e controle foram comparados para MDA e glutationa pelo teste ANOVA e para vitamina E e FOX pelo teste de Kruskal Wallis. Em todas as análises, foi considerado o nível de significância de $5 \%(\mathrm{p}<0,05)$.

\section{Resultados}

Os níveis de hidroperóxidos foram significativamente mais elevados no Grupo Endometriose em relação ao Grupo Controle $(8,9 \pm 1,8 \mu \mathrm{Mol} / \mathrm{g}$ proteína e $8,0 \pm 2,0 \mu \mathrm{Mol} / \mathrm{g}$ proteína, respectivamente). Da mesma forma, os níveis de hidroperóxidos foram significativamente mais elevados no grupo endometriose III/IV em relação aos grupos endometriose I/II $(9,7 \pm 2,3 \mu \mathrm{Mol} / \mathrm{g}$ proteína e $8,2 \pm 1,0$ $\mu \mathrm{Mol} / \mathrm{g}$ proteína, respectivamente) (Tabela 1 ).

Não houve diferença significativa entre os níveis séricos de vitamina $\mathrm{E}$ e glutationa entre os grupos endometriose e controle. Os níveis de vitamina E e glutationa foram significativamente mais baixos no soro de mulheres inférteis com endometriose III/IV quando comparadas a mulheres com endometriose I/II (vitamina E: 21,7 $\pm 6,0$ $\mu \mathrm{mol} / \mathrm{L}$ versus $28,3 \pm 14,4 ; \mathrm{GSH}: 199,6 \pm 56,1 \mathrm{nmol} / \mathrm{L}$ versus $159,6 \pm 77,2 \mathrm{nmol} / \mathrm{L}$; respectivamente) (Tabela1).

Não foram encontradas diferenças entre os níveis séricos de malondialdeído quando comparados os grupos endometriose e controle $(23,1 \pm 7,5 \mu \mathrm{mol} / \mathrm{g}$ pt e $22,0 \pm 9,1$ $\mu \mathrm{mol} / \mathrm{g} \mathrm{pt}$, respectivamente), nem entre os grupos endometriose I/II, endometriose III/IV e controle $(23,3 \pm 8,7$ $\mu \mathrm{mol} / \mathrm{g}$ pt, $22,8 \pm 5,8 \mu \mathrm{mol} / \mathrm{g}$ pt e $22,0 \pm 9,1 \mu \mathrm{mol} / \mathrm{g} \mathrm{pt}$, respectivamente). Do mesmo modo, não foram observadas diferenças associadas ao estadiamento da doença e os níveis séricos de MDA (Tabela 1).

\section{Discussão}

A endometriose é uma doença que frequentemente está associada à infertilidade e em cuja etiopatogênese possivelmente está envolvida uma resposta inflamatória aos implantes endometriais ectópicos ${ }^{24}$. Esses implantes ectópicos estimulariam a liberação de citocinas inflamatórias e ativação de macrófagos, levando à produção de espécies reativas do oxigênio e do nitrogênio ${ }^{12}$. A maior produção de espécies reativas pode desencadear um maior consumo de antioxidantes não-enzimáticos e/ou alteração da expressão gênica e atividade das principais enzimas

Tabela 1 - Comparação entre os níveis séricos de hidroperóxidos (FOX $)$, vitamina E, glutationa (GSH) e malondialdeído (MDA) entre pacientes com fator tubário e/ou masculino de infertilidade (Grupo Controle), endometriose, endometriose mínima e leve (I/II) e endometriose moderada e severa (III/IV)

\begin{tabular}{|c|c|c|c|c|c|c|c|}
\hline & Controle & Endometriose & Valor de $\mathrm{p}$ & Endometriose I/II & Endometriose III/IV & Valor de p & Valor de $\mathrm{p}^{*}$ \\
\hline $\mathrm{FOX}_{1}(\mathrm{pMol} / \mathrm{g} \mathrm{pt})$ & $8,0 \pm 2,0$ & $8,9 \pm 1,8$ & 0,002 & $8,2 \pm 1,0$ & $9,7 \pm 2,3$ & 0,005 & 0,002 \\
\hline Vitamina $E(p M o l / L)$ & $23,2 \pm 6,6$ & $25,5 \pm 11,9$ & 0,4 & $28,3 \pm 14,4$ & $21,7 \pm 6,0$ & 0,04 & 0,08 \\
\hline MDA (nMol/g pt) & $22,0 \pm 9,1$ & $23,1 \pm 7,5$ & 0,5 & $23,3 \pm 8,7$ & $22,8 \pm 5,8$ & 0,8 & 0,8 \\
\hline
\end{tabular}

FOX : total de hidroperóxidos, GSH: glutationa, MDA: malodialdeído, pt: proteína, *valores de p quando comparados os grupos controle, endometriose $1 /$ II e endometriose III/IV. Dados representados em média \pm desvio padrão. 
antioxidantes, na tentativa de se manterem os níveis de espécies reativas dentro dos limites fisiológicos. Todavia, quando ocorre um desbalanço entre a produção e neutralização das espécies reativas, seja por maior produção e/ou inadequação da capacidade antioxidante, é estabelecido o estresse oxidativo que, segundo algumas evidências, participaria da etiopatogênese da endometriose e poderia cursar com comprometimento da fertilidade natural e piora dos resultados de reprodução assistida ${ }^{4-7}$. Dispomos de dados inconclusivos acerca do balanço oxidante-antioxidante em portadoras de endometriose, sendo pouco elucidado se há apenas presença de aumento de produção de espécies reativas ou se haveria também uma alteração do sistema antioxidante inerente à doença. Outro ponto pouco estudado é se o estresse oxidativo, potencialmente presente no fluido peritoneal de portadoras de endometriose pélvica, também seria detectado em nível sistêmico. Nesse sentido, objetivamos avaliar alguns marcadores de estresse oxidativo no soro de mulheres inférteis com e sem endometriose na fase folicular precoce do ciclo menstrual.

No presente estudo, evidenciou-se, pela primeira vez na literatura, um aumento significativo do total de hidroperóxidos no soro de portadoras de infertilidade relacionada à endometriose quando comparadas a mulheres com infertilidade por fatores masculino e/ou tubário, sugerindo a maior produção de espécies reativas nesse grupo de pacientes, detectável em nível sistêmico. Observou-se, também, um aumento do total de hidroperóxidos em portadoras de endometriose pélvica moderada e severa em relação a mulheres com doença mínima e leve, sugerindo uma associação significativa entre o aumento de produção de espécies reativas e o estadiamento da doença. Considerando que as portadoras de doença moderada e severa apresentam maior quantidade de implantes endometriais ectópicos, passíveis de maior produção de espécies reativas na cavidade pélvica, sugerimos que este fato possa contribuir para o presente achado, o que precisa ser avaliado por meio de estudos futuros com metodologia pertinente.

Foram observados níveis de vitamina E e glutationa significativamente menores nas portadoras de endometriose moderada e grave quando comparadas às mulheres com doença mínima e leve, sugerindo uma associação entre a redução desses antioxidantes não-enzimáticos e a maior severidade da doença, detectável em nível sistêmico. Considerando a fisiopatologia da endometriose pélvica e o maior número de implantes ectópicos associados à maior severidade da doença, com consequente aumento da produção de espécies reativas, é hipotetizado que essa redução de antioxidantes possa ser decorrente do seu maior consumo na tentativa endógena de prevenção do estresse oxidativo sistêmico.

Não houve diferença significativa quanto os níveis séricos de malondialdeído (MDA) em comparação às pacientes com infertilidade relacionada à endometriose e às controles. Esses dados são compatíveis com relatos anteriores que não demonstram aumento de MDA no soro e fluido peritoneal de mulheres com endometrio$\mathrm{se}^{25}$. Apesar das controvérsias presentes na literatura, os presentes achados não evidenciam aumento da peroxidação lipídica sistemicamente identificável neste grupo de pacientes.

É importante ressaltar que a primeira fase do estresse oxidativo é iniciada pela maior produção de espécies reativas, como identificado no presente estudo pelo aumento da produção de hidroperóxidos em portadoras de endometriose. A segunda fase envolve o início das reações dos radicais livres aos seus principais alvos e consumo de antioxidantes no sentido de prevenir a ocorrência de danos oxidativos. Nesta fase, a vitamina E é fundamental para prevenir ou interromper a propagação da peroxidação lipídica. Tanto para neutralizar as espécies reativas produzidas como para reciclar a vitamina E oxidada, pode ocorrer o consumo de glutationa reduzida, cuja síntese de novo também é inibida pelas espécies reativas produzidas ${ }^{6,13,18}$. $\mathrm{Na}$ terceira fase é que ocorre o dano oxidativo em virtude da progressão do estresse oxidativo, com aumento da peroxidação de lipídios e outros alvos das espécies reativas. Isto evidencia que a peroxidação lipídica seria um passo final de evolução do estresse oxidativo, sendo precedida por processos bioquímicos que levam à formação de diferentes moléculas que poderiam ser importantes alvos de terapias antioxidantes ${ }^{18}$.

Desta forma, analisando em conjunto os presentes dados, evidenciamos a presença de estresse oxidativo sistêmico em portadoras de infertilidade relacionada à endometriose, que se caracteriza pela maior produção de hidroperóxidos e redução dos antioxidantes, vitamina $\mathrm{E}$ e glutationa. Apesar de haver poucos trabalhos em que se analisam os marcadores de estresse oxidativo sistêmico em portadoras de endometriose, os presentes achados são concordantes com os de alguns estudos publicados. Shanti et al. ${ }^{26}$ evidenciaram que pacientes com endometriose apresentam níveis séricos significativamente mais elevados de autoanticorpos contra proteínas oxidadas do que controles saudáveis. Jackson et al. ${ }^{27}$ demonstraram uma associação entre os níveis séricos de espécies reativas ao ácido tiobarbitúrico e endometriose, sugerindo que o estresse oxidativo possa participar do desenvolvimento e progressão da doença. Em estudo recentemente publicado, Lambrinoudaki et al. ${ }^{28}$ observaram níveis circulantes mais elevados de HSP70b' (proteína do choque térmico 70) em portadoras de endometriose do que no grupo controle, sugerindo que o estresse oxidativo em mulheres com endometriose pélvica poderia não estar restrito à cavidade pélvica, atingindo a circulação sistêmica, com potenciais repercussões não-reprodutivas. 
Apesar da presença de estresse oxidativo sistêmico em portadoras de infertilidade relacionada à endometriose, como evidenciado no presente estudo, observou-se que o consequente consumo de antioxidantes, como a glutationa e a vitamina $\mathrm{E}$, parecem prevenir a ocorrência de peroxidação lipídica sistêmica, uma vez que observamos níveis séricos de malondialdeído similares nas portadoras de infertilidade relacionada à endometriose e nas pacientes controles. $\mathrm{O}$ maior aumento dos níveis de hidroperóxidos e a redução da glutationa e vitamina $\mathrm{E}$ observados em portadoras de endometriose moderada e grave sugerem que o estresse oxidativo sistêmico esteja associado à maior gravidade da doença e, possivelmente, à maior quantidade de focos endometriais ectópicos. As implicações reprodutivas e metabólicas do estresse oxidativo sistêmico precisam ser avaliadas em futuros estudos, assim como a aplicabilidade de terapias antioxidantes na melhora da fertilidade natural e resultados dos procedimentos de reprodução assistida neste grupo de mulheres.

\section{Agradecimentos}

À Fundação de Amparo à Pesquisa do Estado de São Paulo (Fapesp), processo 2008/58197-6; ao Conselho Nacional de Desenvolvimento Científico e Tecnológico (CNPq), processo 474858/2009-0; e ao Instituto Nacional de Ciências e Tecnologia (INCT/CNPq) Hormônios e Saúde da Mulher.

Aos funcionários do Laboratório de Reprodução Assistida do Hospital das Clínicas, Departamento de Ginecologia e Obstetrícia, Faculdade de Medicina de Ribeirão Preto, Universidade de São Paulo e do Laboratório de Nutrição e Metabolismo, Departamento de Clínica Médica pelo apoio técnico prestado.

\section{Referências}

1. Van Langendonckt A, Casanas-Roux F, Donnez J. Oxidative stress and peritoneal endometriosis. Fertil Steril. 2002;77(5):861-70.

2. Gupta S, Goldberg JM, Aziz N, Goldberg E, Krajcir N, Agarwal A. Pathogenic mechanisms in endometriosis-associated infertility. Fertil Steril. 2008;90(2):247-57.

3. Ozkan S, Murk W, Arici A. Endometriosis and infertility: epidemiology and evidence-based treatments. Ann N Y Acad Sci. 2008;1127:92-100.

4. Agarwal A, Saleh RA, Bedaiwy MA. Role of reactive oxygen species in the pathophysiology of human reproduction. Fertil Steril. 2003;79(4):829-43.

5. Szczepanska M, Kozlik J, Skrzypczak J, Mikolajczyk M. Oxidative stress may be a piece in the endometriosis puzzle. Fertil Steril. 2003;79(6): 1288-93.

6. Gupta S, Agarwal A, Krajcir N, Alvarez JG. Role of oxidative stress in endometriosis. Reprod Biomed Online. 2006;13(1):126-34.

7. Augoulea A, Mastorakos G, Lambrinoudaki I, Christodoulakos G, Creatsas $G$. The role of the oxidative-stress in the endometriosisrelated infertility. Gynecol Endocrinol. 2009;25(2):75-81.

8. Halliwell B, Cross CE. Oxygen-derived species: their relation to human disease and environmental stress. Environ Health Perspect. 1994;102 Suppl 10:5-12.

9. Murphy AA, Santanam N, Morales A, Parthasarathy S. Lysophosphatidyl choline, a chemotactic factor for monocytes/Tlymphocytes is elevated in endometriosis. J Clin Endocrinol Metab. 1998;83(6):2110-3.

10. Van Langendonckt A, Casanas-Roux F, Donnez J. Iron overload in the peritoneal cavity of women with pelvic endometriosis. Fertil Steril. 2002;78(4):712-8.

11. Alpay Z, Saed GM, Diamond MP. Female infertility and free radicals: potential role in adhesions and endometriosis. J Soc Gynecol Investig. 2006;13(6):390-8.

12. Agarwal A, Gupta S, Sharma RK. Role of oxidative stress in female reproduction. Reprod Biol Endocrinol. 2005;3:28.
13. Fujii J, luchi Y, Okada F. Fundamental roles of reactive oxygen species and protective mechanisms in the female reproductive system. Reprod Biol Endocrinol. 2005;3:43.

14. Ruder EH, Hartman TJ, Blumberg J, Goldman MB. Oxidative stress and antioxidants: exposure and impact on female fertility. Hum Reprod Update. 2008;14(4):345-57.

15. Gutteridge JM, Halliwell B. Iron toxicity and oxygen radicals. Baillieres Clin Haematol. 1989;2(2):195-256.

16. Campos Petean C, Ferriani RA, dos Reis RM, de Moura MD, Jordao AA, Jr., Navarro PA. Lipid peroxidation and vitamin $E$ in serum and follicular fluid of infertile women with peritoneal endometriosis submitted to controlled ovarian hyperstimulation: a pilot study. Fertil Steril. 2008;90(6):2080-5.

17. Liu $Y$, Luo L, Zhao H. Levels of lipid peroxides and superoxide dismutase in peritoneal fluid of patients with endometriosis. J Tongji Med Univ. $2001 ; 21$ (2):166-7.

18. Nwose EU, Jelinek HF, Richards RS, Kerr PG. The 'vitamin E regeneration system' (VERS) and an algorithm to justify antioxidant supplementation in diabetes-a hypothesis. Med Hypotheses. 2008;70(5): 1002-8.

19. de Matos DG, Furnus CC. The importance of having high glutathione (GSH) level after bovine in vitro maturation on embryo development effect of beta-mercaptoethanol, cysteine and cystine. Theriogenology. 2000;53(3):761-71.

20. Galli F, Piroddi M, Annetti C, Aisa C, Floridi E, Floridi A. Oxidative stress and reactive oxygen species. Contrib Nephrol. $2005 ; 149: 240-60$.

21. Arnaud J, Fortis I, Blachier S, Kia D, Favier A. Simultaneous determination of retinol, alpha-tocopherol and beta-carotene in serum by isocratic high-performance liquid chromatography. J Chromatogr. 1991;572(1-2):103-16.

22. Ellman GL. Tissue sulfhydryl groups. Arch Biochem Biophys. 1959;82(1):70-7.

23. Hu ML. Measurement of protein thiol groups and glutathione in plasma. Methods Enzymol. 1994;233:380-5. 
24. Murphy AA, Santanam N, Parthasarathy S. Endometriosis: a disease of oxidative stress? Semin Reprod Endocrinol. 1998;16(4):263-73.

25. Polak G, Koziot-Montewka M, Tarkowski R, Kotarski J. Peritoneal fluid and plasma 4-hydroxynonenal and malonyldialdehyde concentrations in infertile women. Ginekol Pol. 2001;72(12A): 1316-20.

26. Shanti A, Santanam N, Morales A, Parthasarathy S, Murphy AA. Autoantibodies to markers of oxidative stress are elevated in women with endometriosis. Fertil Steril. 1999;71(6):1115-8.
27. Jackson LW, Schisterman EF, Dey-Rao R, Browne R, Armstrong D. Oxidative stress and endometriosis. Hum Reprod. 2005;20(7):2014-20.

28. Lambrinoudaki IV, Augoulea A, Christodoulakos GE, Economou EV, Kaparos G, Kontoravdis A, et al. Measurable serum markers of oxidative stress response in women with endometriosis. Fertil Steril. $2009 ; 91(1): 46-50$. 